\title{
Theodor Demetriades zum Gedächtnis
}

Von seineni schweren Leiden erlöst, verstarb Ende Juli 19(30 in seiner Heimatstadt der o. Prof. Th. Demetriades der Universität Athen nach laiigwieriger Krankheit. Theodor Demetriades wurde als Sohn des Universilätsprofessors St. Demetriades, der ebenfalls Oto-Rhino-

Laryngologe war, in Athen geboren, besuchte dort das Gymnasium und absolvierte seine Studien an der Athener Medi-zinischen Fakultät. Im ersten Weltkrieg, im Griechisch-Türki-schen Krieg und schließlich im letzten Weltkrieg leistete er ats Sanitälsofñzier Militärdienst.

Seine erste Ausbildung genoß er bei seineni Vater. Dann kam er im Jahr 1923 nach Wien, wo er an den Kliniken Alexander-Hajek-Neumann seine Fachstudien vollendete und sich 1927 als Privatdozent habilitierte. Im Jahre 1930 übernahm er die Oto-Rhino-Laryngologische Abteilung des Roten Kreuz-Krankenhauses in Athen, und im Jahre 1939 wurde er zum Professor an der Universität Athen ernannt, wo er von Anfang an zu den führenden Otorhinolaryngologen zählte. Seine zahlreichen wissenschaftlichen Arbeiten beziehen sich hauptsächlich auf die Otologie, aber auch in den anderen Gebie-ten unseres Spezialfaches hat er vieles publiziert. Er war ein verdienter Mitarbeiter der Practica Oto-Rhino-Laryngologica.

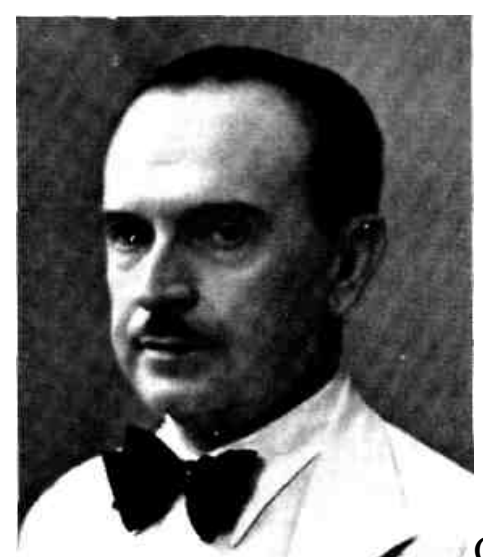

G. E. Yannouiís, Thessaloniki 